\title{
BMJ Open Multinational comparison of new antidepressant use in older adults: a cohort study
}

\author{
Robyn Tamblyn, ${ }^{1}$ David Westfall Bates, ${ }^{2}$ David L Buckeridge, ${ }^{3,4}$ Will Dixon, ${ }^{5}$ \\ Alan J Forster, ${ }^{6,7}$ Nadyne Girard, ${ }^{8}$ Jennifer Haas, ${ }^{9}$ Bettina Habib, ${ }^{8}$ Siyana Kurteva, ${ }^{3}$ \\ Jack Li, ${ }^{10}$ Therese Sheppard ${ }^{11}$
}

\begin{abstract}
To cite: Tamblyn R, Bates DW, Buckeridge DL, et al. Multinational comparison of new antidepressant use in older adults: a cohort study. BMJ Open 2019;9:e027663. doi:10.1136/ bmjopen-2018-027663

- Prepublication history and additional material for this paper are available online. To view these files, please visit the journal online (http://dx.doi. org/10.1136/bmjopen-2018027663).
\end{abstract}

Received 7 November 2018

Revised 13 March 2019

Accepted 28 March 2019
Check for updates

(C) Author(s) (or their employer(s)) 2019. Re-use permitted under CC BY-NC. No commercial re-use. See rights and permissions. Published by BMJ.

For numbered affiliations see end of article.

Correspondence to Dr Robyn Tamblyn; robyn.tamblyn@mcgill.ca

\section{ABSTRACT}

Objectives We used an international

pharmacosurveillance network to estimate the rate and characteristics of antidepressant use in older adults in countries with more conservative (UK) and liberal depression guidelines (Canada, USA).

Setting Electronic health records and population-based administrative data from six jurisdictions in four countries (UK, Taiwan, USA and Canada).

Participants A historical cohort of older adults ( $\geq 65$ years) who had a new episode of antidepressant use between 2009 and 2014.

Outcome measures The age and sex-standardised cumulative incidence of new episodes of antidepressant use in older adults was measured. Descriptive statistics were used to compare the proportion of new users by the antidepressant prescribed, therapeutic class, potential treatment indication and country, as well as the characteristics of the first treatment episode (standardised daily doses, duration and changes).

Results The incidence of antidepressant use between 2009 and 2014 varied from 4.7\% (Montreal and Quebec City) to $18.6 \%$ (Taiwan). Tricyclic antidepressants (TCAs) were the most commonly used class in the UK (48.8\%) and Taiwan (52.4\%) compared with selective serotonin reuptake inhibitors (SSRIs) in North American jurisdictions $(42.3 \%-53.3 \%)$. Chronic pain was the most common potential treatment indication $(41.2 \%-68.2 \%)$. Among users with chronic pain, TCAs were used most frequently in the UK and Taiwan $(55.2 \%-60.4 \%)$, whereas SSRIs were used most frequently in North America (33.5\%-46.4\%). Treatment was longer (252525 vs 169-437 days), standardised doses were higher (0.7-1.3 vs $0.5-1.0)$ and treatment was more likely to be changed $(31 \%-46 \%$ vs $21 \%-34 \%)$ among patients with depression $(9.1 \%-43 \%)$ than those with chronic pain.

Conclusion Antidepressant use in older adults varied 24 -fold by country, with the UK, which has the most conservative treatment guidelines, being among the lowest. Chronic pain was the most common potential treatment indication. Evaluation of real-world risks of TCAs is a priority for future research, given high rates of use and the potential for increased toxicity in older adults because of potent anticholinergic effects.

\section{Strengths and limitations of this study}

- Uses an international pharmacosurveillance network to characterise antidepressant use across multiple jurisdictions.

- Despite data harmonisation efforts, measurement and reporting issues may lead to arbitrary differences between regions and countries.

- Treatment indication is unknown for all but one study cohort. Documentation of health problems in medical services billing data and electronic medical records was used as a proxy for treatment indication for remaining cohorts, which could have resulted in misclassification bias.

- While some cohorts represented total populations or representative samples, others were assembled from practices supported by specific information technology systems.

\section{INTRODUCTION}

Depression affects an estimated 300 million people worldwide. ${ }^{1}$ In the past decade, many countries have reported a twofold to threefold increase in the use of antidepressant medications. ${ }^{2}$ The primary increase has been in newer antidepressants such as selective serotonin reuptake inhibitors (SSRIs), which are considered to have better efficacy than older drugs, with fewer side effects. ${ }^{3}$ Increasing prevalence of use of antidepressants has also been associated with an increase in the number of people started on therapy as well as its duration, with $40 \%$ of antidepressants being prescribed for more than 180 days. ${ }^{4}$ Antidepressants now represent one of the most commonly prescribed medications, ${ }^{56}$ especially among older adults, where the increase in use has been the greatest in the US population. ${ }^{57}$

The increasing use of antidepressants in older adults may be due to a number of factors. There has been long-standing advocacy for better recognition and treatment of depression in older adults. ${ }^{8}$ In addition, individuals with multiple chronic conditions are more likely to experience depression. In Canada, $12 \%$ of 
persons $\geq 65$ years have two or more major chronic conditions compared with only $3.6 \%$ in younger adults; and $4 \%$ of adults with at least one major chronic disease have mood or anxiety disorders, which are other approved indications for antidepressant use. ${ }^{10}$ While increasing prevalence of depression, anxiety and other mood disorders in older adults may account for increasing use of antidepressants, there is also evidence that antidepressants are prescribed for unapproved indications that may not be supported by scientific evidence of efficacy. ${ }^{11-14}$ One recent study found that nearly $50 \%$ of antidepressants were prescribed for unapproved indications including chronic pain, tiredness and sleep disturbance, ${ }^{11}$ which are also more common in older adults. ${ }^{15}$

Taken together, these factors have led to increasing concern about overuse of antidepressants, particularly in older adults. ${ }^{16}$ This concern is heightened because of the reported association between antidepressant use and fall-related injuries, motor vehicle accidents, functional decline and mortality in older adults. ${ }^{17-19}$ Clinical practice guidelines for the management of depression vary considerably in their recommendations for first-line treatment, ${ }^{20-24}$ although most acknowledge the need to consider patient preferences (table 1). The UK NICE guidelines are the most conservative, recommending first-line treatment with psychotherapy such as cognitive behavioural therapy with pharmacotherapy added only if non-pharmacological therapy is unsuccessful. ${ }^{24}$ At the other end of the spectrum, the Canadian 2009 guidelines list pharmacotherapy as a first-line treatment for major depressive disorder, including SSRIs, serotonin-norepinephrine reuptake inhibitors (SNRIs), mirtazapine or bupropion. ${ }^{25-27}$ Of note, Canada ranks the third highest user of antidepressants among 23 Organisation for Economic Co-operation and Development countries, surpassed only by Australia and Iceland. ${ }^{2}$

However, few data are available regarding how national guidelines may contribute to differences in how antidepressants are used for older adults. We took advantage of an international pharmacosurveillance network ${ }^{28}$ that uses electronic medical record (EMR) and population-based health administrative data to estimate the rate of antidepressant use in older adults in countries that had more conservative (UK) and lenient guidelines (Canada, USA, Taiwan). We evaluated differences in the choice of antidepressant, dose and duration of treatment, the prevalence of dose changes and switches in treatment of older adults with new episodes of antidepressant use, as well as differences in treatment approach for patients with a recorded diagnosis of depression, other mental health comorbidities and chronic pain.

\section{METHODS}

\section{Study design and population}

To characterise antidepressant use in older adults, a cohort of individuals who were $\geq 65$ years of age and had a new episode of antidepressant use between 1 January 2009 and 31 December 2014 following 2 years during which they had no prescription or dispensation of an antidepressant was assembled. Eligible patients were identified from EMR or population-based registries in a total of six jurisdictions in four countries (Canada, USA, UK and Taiwan).

\section{Data sources}

Canada

\section{Quebec EMR cohort}

Data were extracted from the Medical Office of the 21st Century (MOXXI) EMR, which includes a real-time linkage to the Quebec insurance agency, the Régie de l'assurance maladie du Québec (RAMQ) databases. This linkage provides historical and daily updates of patients' received medical services (diagnosis, procedure, date, location, provider), prescriptions dispensed from community pharmacies for persons who are publicly insured (prescriber, pharmacy, drug, dose, dispensing date, duration, refills) and mortality. Approximately 110 primary care physicians in Quebec use MOXXI for approximately 90000 of their patients, representing approximately $25 \%$ of the patients in the practice, and approximately $5 \%$ of the Quebec population in primary care practices.

\section{Quebec administrative data cohort}

Data were retrieved from the Montreal Population Health Record, a population-based $25 \%$ random sample of the 4.1 million residents of Montreal, Canada's second largest city, which is dynamically updated each year to account for in and out-migration. Beneficiary characteristics were measured by linking the RAMQ beneficiary database (age, sex, postal code) with Statistics Canada's census file (postal code level measures of socioeconomic status) and the Institute of Statistics birth and death registry (date of birth and death). From this population-based dataset, we identified all non-institutionalised persons $\geq 65$ years of age between 2009 and 2014. All medical services (date, diagnosis, procedure), hospitalisations (admission and discharge date, primary and secondary diagnoses, in-hospital procedures) and medications (prescriber, pharmacy, drug, dose, dispensing date, duration, refills) received by members of the cohort were retrieved from the RAMQ database and those of the Quebec Ministry of Health.

\section{Ontario administrative data cohort}

Data were extracted from the Institute for Clinical Evaluative Sciences population-based repository of health records for the 13.6 million Ontario residents. The data are provided by the Ontario Ministry of Health and LongTerm Care, which pays for all essential health services. For the 2053588 Ontario non-institutionalised residents who were $\geq 65$ years between 2007 and 2014, we randomly sampled $20 \%$ and extracted age, sex and date of death from the beneficiary registrants database, all billing claims for medical services provided by Ontario physicians (date of service, diagnosis, procedure code, physician provider), all claims for medications dispensed in the community by Ontario pharmacies (drug, date dispensed, prescriber, 


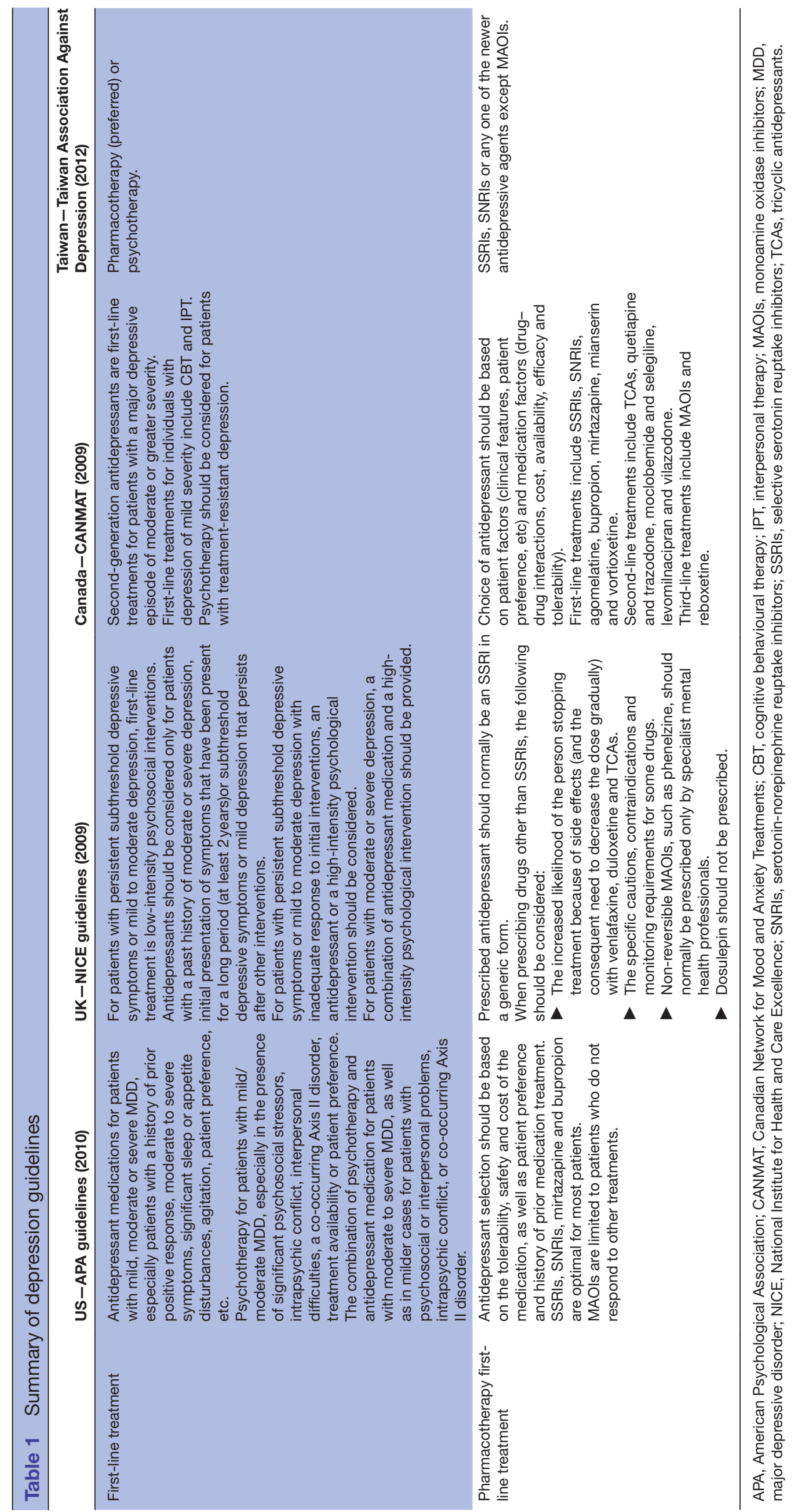


quantity, duration, number of refills) and data from discharge summaries of emergency department visits and hospital stays (date of admission and discharge, primary and secondary diagnoses and procedures).

\section{USA}

\section{Boston, Massachusetts EMR cohort}

Data were extracted from the Partners HealthCare Research Patient Data Registry (RPDR), which provides care for approximately 3 million of 5 million residents in Boston and surrounding areas. RPDR includes data from the longitudinal medical record (LMR), an internally developed, web-based, fully functional EMR that was in use during this period for the participating primary care clinics from Brigham and Women's Hospital (BWH) and Massachusetts General Hospital (MGH), the two founding members of Partners Healthcare in Boston, Massachusetts. Data were retrieved from the structured clinical encounter information from RPDR for all outpatient primary care visits. To ensure complete follow-up, patients were eligible if they were seen in one of $37 \mathrm{BWH}$-affiliated or MGH-affiliated primary care or diabetes clinics.

\section{UK}

\section{EMR cohort}

Data were extracted from the Clinical Practice Research Datalink (CPRD), an anonymised LMRs database for primary care. The primary care EHR includes information on all primary care interactions, including documented health problems, visit notes, prescriptions and records of specialty referrals, as well as information on lab results, hospitalisations and death. The CPRD includes more than 4 million active patients, $76 \%$ of whom are in England, representing $6.9 \%$ of the 64 million primary care population in the UK, and around 600 primary care practices. ${ }^{29}$ Patients were included if their records met minimum quality standards and there were no gaps in registration. A 10\% random sample of the 2436180 elderly patients in the database were extracted.

\section{Taiwan}

\section{Administrative data cohort}

Data were extracted from the Taiwanese National Health Insurance (NHI) system databases. The NHI provides health coverage to around $99 \%$ of Taiwan's population of 23 million, providing comprehensive coverage for all health services, including dental, preventive, Western medicine and traditional Chinese medicine services. A random sample of 103400 of the 3.6 million residents who were $\geq 65$ years in Taiwan between 2007 and 2014 was extracted for this study. The NHI's research databases include a registry for beneficiaries (eg, registrant's age, sex and residence), an outpatient visit database (date and time of visit, ICD-9-CM codes of existing health problems, service provided), an inpatient visit database (date of hospitalisation and discharge, ICD-9-CM codes of existing health problems, procedure codes and dates) and a pharmacy database (drug prescribed, date, duration, dosage, prescribing physician, dispensing pharmacy).

\section{Measurement \\ Patient characteristics \\ Age and sex}

Date of birth and sex were retrieved from the administrative data in Canada and Taiwan as these data are verified at the time of enrollment in the health plan. For the USA and UK, these data were retrieved from the EMR.

Depression, other mental health comorbidities and chronic pain

We measured the existence of potential indications for antidepressant use ${ }^{1112}$ including depression, other mental health conditions and chronic pain. Depression included mild, moderate, major single or recurrent depressive disorder with or without psychotic symptoms, adjustment reaction and mixed anxiety and depression. Other mental health conditions included anxiety, alcohol abuse, illicit drug use, attempted suicide, psychosis, schizophrenia and bipolar disorder. Anxiety included dissociative and somatoform disorders. We used standard diagnostic codes (ICD 9, ICD 10 and Read codes) retrieved from the EMR, and/or medical services claims, and hospitalisations in the 2 years prior to the first antidepressant prescription to measure these conditions (see online supplementary appendix).

To measure chronic pain, we used a previously validated ICD9 and ICD10 code set for non-cancer pain. ${ }^{30}$ The concepts and definitions used in the development and validation of this code set were used to map to Read codes (appendix available on request). Chronic non-cancer pain conditions included lumbar pain, back disorders that are often associated with pain (eg, degenerative disc disease), neck and back problems (eg, spondylosis), fibromyalgia, complex regional pain syndromes (eg, mononeuritis), painful neuropathic disorders (eg, postherpetic neuralgia), pain disorders with psychosocial dysfunction and unclassified chronic pain problems.

\section{Characterising antidepressant use}

The characteristics of antidepressant use were compared in the population of seniors with a new episode of antidepressant use in each country, overall and then within subgroups that had a diagnosis of (a) depression, (b) chronic pain or (c) other mental health problems.

\section{Classification of starting therapy}

The Anatomic Therapeutic Classification system ${ }^{31}$ was used to map national drug names and identification numbers to a common nomenclature based on the antidepressants that were prescribed during the study time period. Therapeutic classes included tricyclic antidepressants (TCAs), SSRIs, SNRIs, serotonin antagonist and reuptake inhibitors (SARIs), norepinephrine-dopamine reuptake inhibitors (NDRIs), noradrenergic and specific serotonergic antidepressants, tetracyclic antidepressants, melatonergic agonists and NRIs. Monoamine oxidase inhibitors were excluded as they are rarely used and only 
for bipolar disorder. Starting therapy was classified by therapeutic class and drug, and by the number of antidepressants prescribed at treatment initiation.

\section{Starting antidepressant dose}

To enable comparisons in the dose prescribed among antidepressants, we created a standardised dose for each drug by dividing the prescribed dose by the WHO recommended daily dose for adults. The resulting indicator represents the proportion of the recommended daily adult dose that was prescribed. When more than one antidepressant was prescribed concurrently, we summed the standardised dose for each drug.

\section{Analysis}

The cumulative incidence of older adults with new episodes of antidepressant use in the period 2009 to 2014 was measured by dividing the number of new users by the total population that was $\geq 65$ years during this time period. Rates were standardised for age and sex using the direct method and the UK as the reference population. New episodes of use were defined as those who had no prior prescription of an antidepressant in the 2 years preceding their first prescription. Descriptive statistics were used to compare the proportion of new antidepressant users by the antidepressant prescribed, therapeutic class, country and potential treatment indication, as well as the characteristics of the first treatment episode. As the coexistence of other mental health conditions may modify treatment choices, we used the prevalence ratio to estimate the concurrence of other mental health problems, chronic pain and depression. The prevalence ratio allowed us to compare between countries even if the prevalence of these conditions is different. ${ }^{32}$ It was calculated as the prevalence of the health problem of interest among individuals with depression, divided by the prevalence of the health problem among individuals without depression.

\section{Patient and public involvement}

Patients and members of the public were not involved in the development of research questions or outcome measures, design or implementation of this study. There are no plans to involve patients in dissemination of research results.

\section{RESULTS}

The age-standardised cumulative incidence of antidepressant use in persons aged $\geq 65$ in the period 20092014 was highest in Taiwan (18.6\%) and Ontario, Canada $(15.3 \%)$, and lowest in Quebec-Montreal (4.7\%) and England (6.6\%) (table 2). Simlarly, the overall prevalence of antidepressant use in the same time period was lowest in England (10.3\%), and highest in Ontario, Canada $(26.8 \%)$ and Taiwan $(23.4 \%)$. The distribution of age was similar in all jurisdications.
Frequency distribution of the first antidepressant prescription by therapeutic class

Overall, there were substantial differences between jurisdictions in the choice of starting therapy for new users (table 3). Tricyclic antidepressants were the most commonly used class of antidepressants in England $(48.8 \%)$ and Taiwan $(52.4 \%)$ compared with SSRIs in North American jurisdictions $(42.3 \%-53.3 \%)$. Notably, in the UK, approximately one-quarter of antidepressant prescriptions were for newer classes of antidepressants: serotonin antagonist and reuptake inhibitors (trazodone), norepinephrine-dopamine reuptake inhibitors (bupropion) and noradrenergic serotonin-specific antidepressants (mirtazapine).

Coexistence of depression, other mental health problems and chronic pain

The prevalence of a depression diagnosis among new antidepressant users was relatively low, varying from $9.1 \%$ (Taiwan) to $21.7 \%$ (USA). The exception was the EMR cohort in Quebec where the prevalence was $43.0 \%$ (table 4). Among new antidepressant users with a diagnosis of depression, there was a 30\% (UK prevalence ratio: 1.3) to sevenfold (USA prevalence ratio: 7.3) increase in the likelihood of also having an alcohol or other substance abuse problem. Anxiety, which varied from being present in $12.1 \%$ of new antidepressant users in the UK to $47.8 \%$ of new users in Taiwan, was the most common mental health problem, and was also more likely to be present among persons with depression (Prevalence ratio: 1.3 [Ontario, Quebec] to 3.6 [USA]). Although less common in all jurisdictions, both major mental illness and suicide attempt were more likely to be present among antidepressant users with depression compared with those without depression. In contrast, chronic pain was the most prevalent problem among new antidepressant users (41.2\% [UK] to $68.2 \%$ [Taiwan]), and was as likely to be present among those with or without depression (Prevalence ratio: 0.9-1.3) (table 4). For almost one-third of new antidepressant users, there was no documented diagnosis of depression, other mental health problems or chronic pain.

\section{Choice of antidepresssant by potential treatment indication}

Among new antidepressant users with a diagnosis of depression, SSRIs were selected as the starting therapy for $55.2 \%$ (Ontario) to $71.4 \%$ (UK), followed by SNRIs in Canadian jurisdictions and newer antidepressants in Boston, the UK and Taiwan (table 5). For antidepressant users with a diagnosis of chronic pain, starting therapy was predominantly with SSRIs in North American jurisdictions $(33.5 \%-46.1 \%)$, and with TCAs in the UK and Taiwan (55.2\%-60.4\%). Selection of therapy for other mental health problems was a mixture of choices made for persons with a diagnosis of depression and chronic pain.

\section{Characteristics of the first treatment episode by potential} treatment indication

Among patients with a diagnosis of depression who were started on antidepressants, 54\% (Ontario) to 68\% 


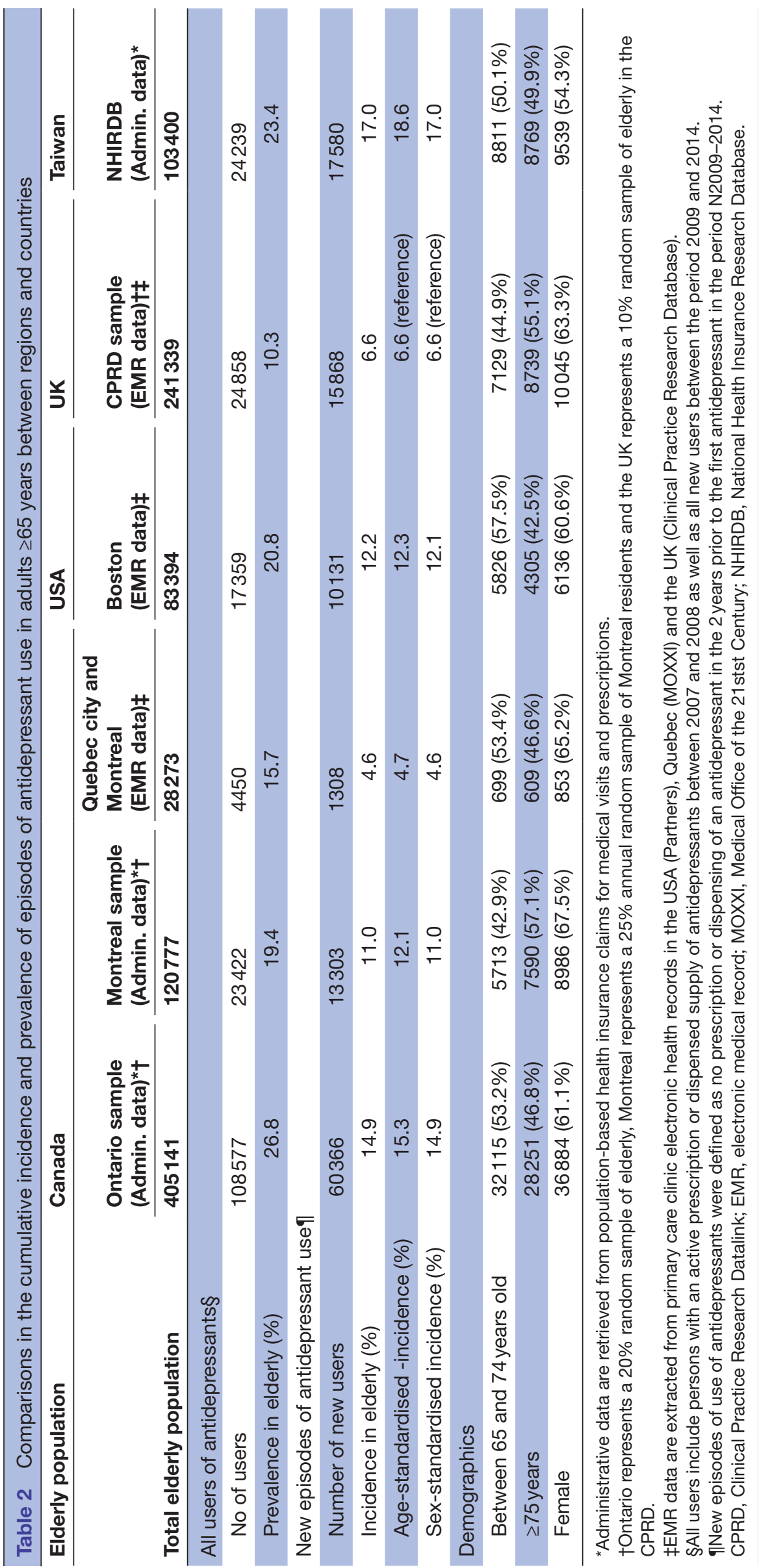

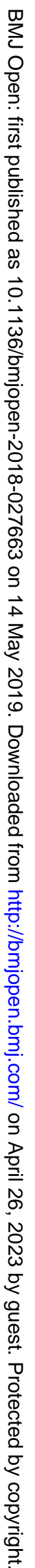




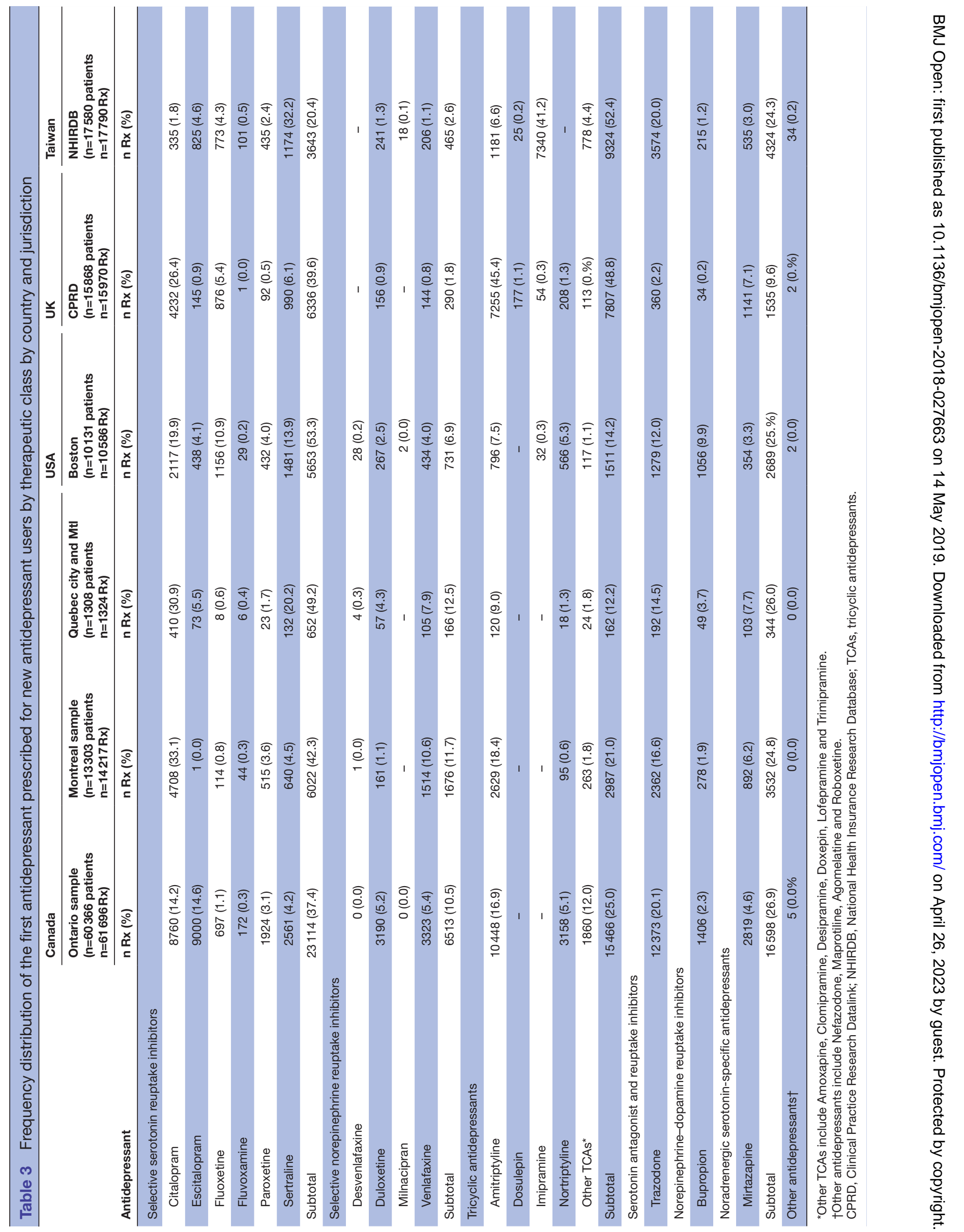




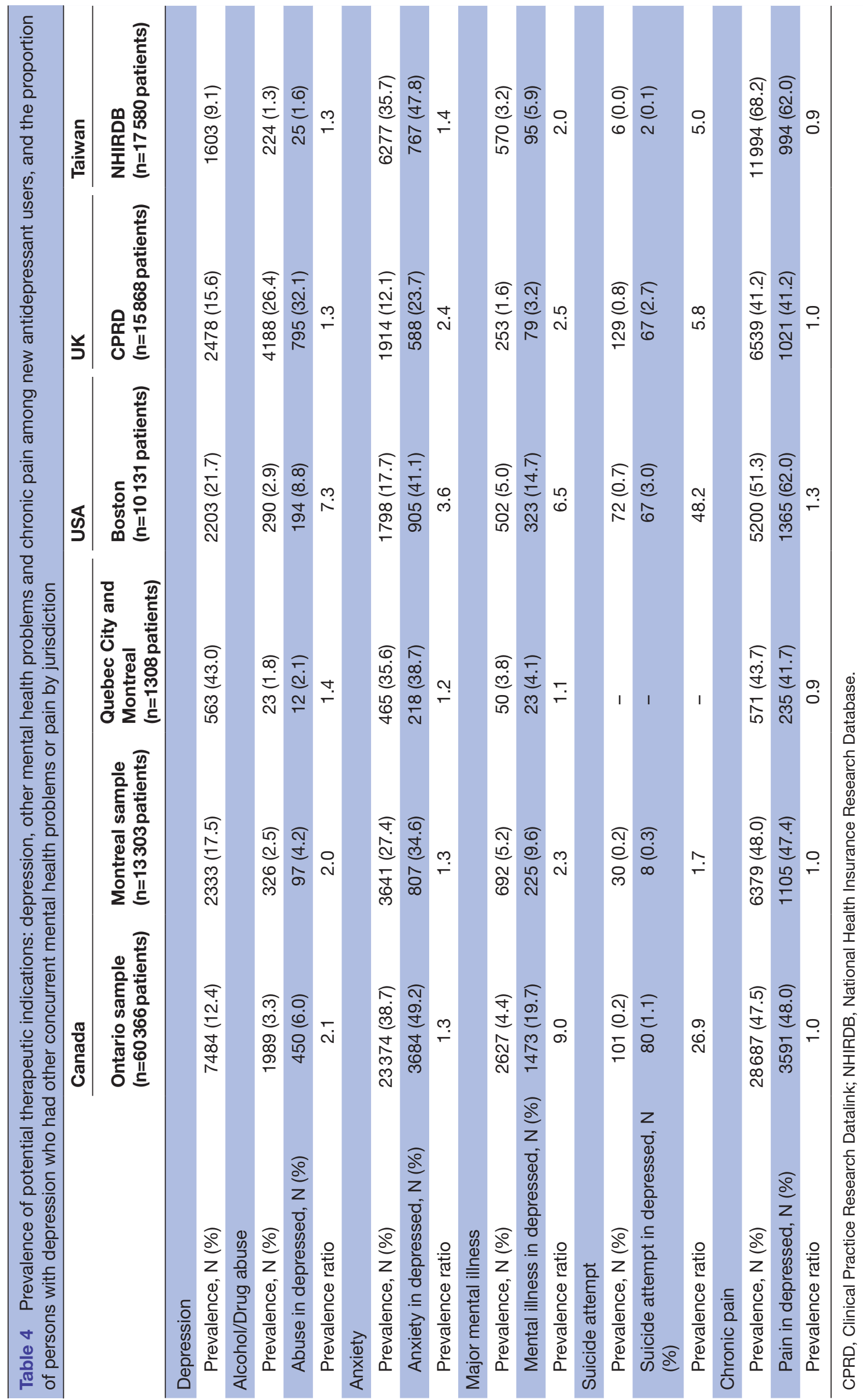

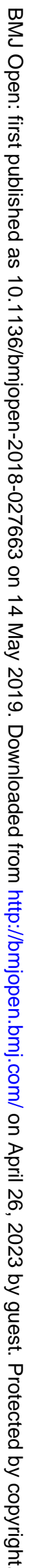




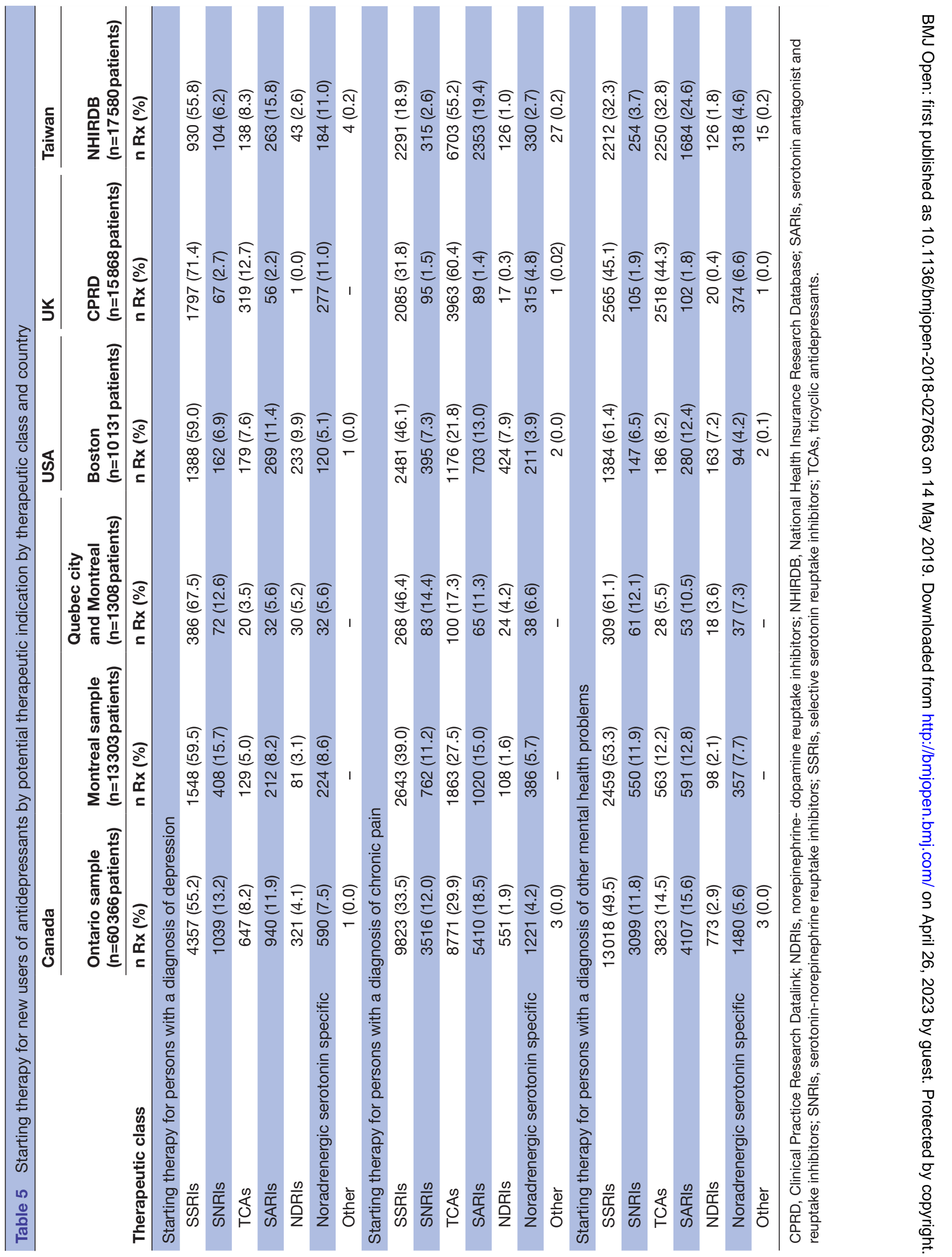


(Taiwan) remained on their initial course of antidepressant treatment (table 6A). For this group, the mean duration of treatment varied from 104.7 (Taiwan) to 340.9 (Quebec) days, and the mean dose varied from 0.6 of the recommended adult dose (Taiwan), to the recommended adult dose in the USA site (mean dose: 1.0). Among the $32 \%$ (Taiwan) to $46 \%$ (Ontario) with a change in treatment, the most common change in all jurisdictions was an increase in dose occurring in 20\% (Taiwan) to $33 \%$ (Ontario) of patients, followed by a decrease in dose (13\% [Taiwan] to $21 \%$ [Ontario]) and the addition of a drug from a different therapeutic class $(6 \%$ [UK] to $18 \%$ [Ontario]). Among patients with a change in therapy in their initial treatment episode, the mean duration of treatment was almost double (mean duration 312.6 to 616.9 days) than for patients with no change, and the mean dose during treatment was substantially higher (mean standardised proportion of the adult dose: 0.8 to 1.4).

The first treatment episode for new antidepressant users with a diagnosis of chronic pain was substantially different from patients with a diagnosis of depression (table 6B). Overall, 66\% (Ontario) to 79\% (Taiwan) were kept on the inititial treatment regimen, for a much shorter duration than for new users with a diagnosis of depression (mean duration: 83.6 days [Taiwan] to 300.9 days [Quebec]), and at lower mean doses (mean standardised proportion of the adult dose: 0.4 [Taiwan, UK, Montreal] to 0.8 [USA]). For the $21 \%-34 \%$ of patients who had a change in treatment, the most common changes in all jurisdictions were an increase in dose $(13 \%$ to $25 \%$ ), a decrease in dose (9\% to $14 \%$ ) and the addition of another drug from a different therapeutic class $(3 \%$ to $11 \%)$. For those with a change in treatment, the duration of the treatment episode was considerably longer in all jurisdictions (264.4-590.0 days), and the mean dose during the treatment episode was higher (0.5-1.1).

\section{INTERPRETATION}

This multinational study is the first to compare the use of antidepressants among comparable cohorts of new users in different countries. We found wide variation in the incidence and prevalence of antidepressant use; the lowest rates included the UK, where guidelines for pharmacotherapy use for depression were the most conservative. Choice of starting therapy also varied widely by country and condition, with the UK and Taiwan more likely to use TCAs for persons with a diagnosis of chronic pain, whereas SSRIs were the most common choice for both depression and pain in North American settings. Overall treatment duration was longer for patients with depression than chronic pain, mean treatment doses were higher and there were more likely to be changes in therapy.

Differences in the incidence of antidepressant use in different countries as well as the choice of antidepressant therapy may also be influenced by a variety of system-related factors. For example, direct to consumer advertising of prescription drugs is permitted in the USA but banned in Canada, Europe and the UK because these ads drive demand for specific treatments. ${ }^{33}$ Also, drugs available and covered by public insurance plans in the UK, Taiwan and Canada are influenced by rigorous reviews and guidelines for the use of new drugs and technologies by national agencies such as the National Institute for Health and Care Excellence in the UK. ${ }^{34-36}$

A surprisingly large percentage of older adults were prescribed antidepressants for conditions other than depression. We found that chronic pain was the most common problem documented, and it appeared to be the most likely reason for antidepressant use. Chronic pain has an estimated prevalence of $11.8 \%{ }^{37}-43.5 \%$ in adults, and increases with age, with an estimated $62 \%$ of those $\geq 75$ years of age experiencing this problem. ${ }^{38}$ While use of antidepressants for chronic pain has been shown to be effective, particularly TCAs (amitriptyline) and SNRIs (duloxetine) for neurogenic pain, ${ }^{39} 40$ TCAs have been on the lists of potentially contraindicated medications for the elderly for over a decade because of their potent anticholinergic effects that can lead to cognitive impairment, and other avoidable morbidity. ${ }^{41}{ }^{42}$ Moreover, only one antidepressant, duloxetine, has been approved for treatment of chronic pain in North America and Europe. ${ }^{11}$ Although the anticholinergic effects of TCAs have been well documented, ${ }^{43-45}$ the actual 'real-world' evidence of harm is limited ${ }^{46}$ and should be addressed in future studies given the high rates of use.

Notably, in this study of older adults, depression was documented in only 2 in 10 users; the exception being in Quebec City/Montreal where 4 out of 10 patients were prescribed antidepressants for depression. There are known problems in underreporting, diagnosis and documentation of depression, ${ }^{47-49}$ which may account for some or all of these differences between sites. The MOXXI system used in the Quebec cohort likely provides an approximate estimate of the extent to which depression is undocumented. In this cohort, physicians are required to document the treatment indication for each drug prescribed, ${ }^{50}$ data that have been validated in prior studies. ${ }^{51}$ Results from this setting suggest that twice as many patients receive antidepressants for depression, whereas a similar proportion of new antidepressant users had a diagnosis of chronic pain as in other sites.

Also, of interest, among patients with documented depression, antidepressant use in all countries followed current guidelines for depression management. ${ }^{21} 245253$ Choice of first-line therapy was predominantly SSRIs and SNRIs. Starting doses were lower than the recommended adult doses, mean duration of treatment was 251-525 days and the main changes in treatment were increases in doses and the addition of an antidepressant from a different therapeutic class. Not surprisingly, among patients where there was a change in treatment, both the average antidepressant dose was higher and treatment duration was longer, suggesting a lack of treatment effectiveness. The 


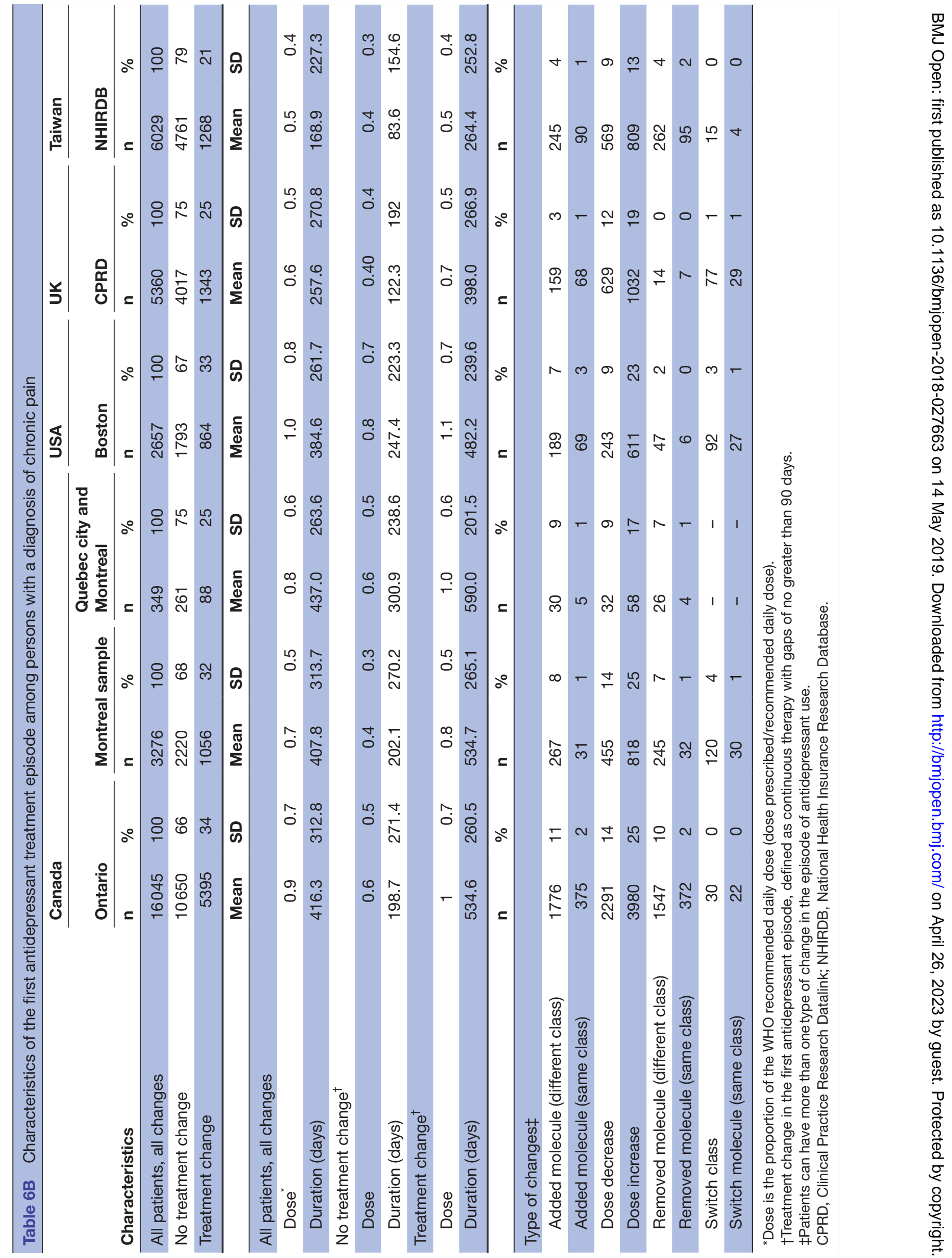


cohort in Taiwan was different in a number of respects including lower antidepressant doses, shorter treatment duration and fewer changes in therapy once started. The reason for these differences in approach is not clear. They may represent an innate conservatism in the use of antidepressants in the Taiwanese population where there is an acknowledged absence of evidence to support clinical guidelines, ${ }^{53}$ or known differences in genetic determinants of drug metabolism that have been established in population-based genomic studies of drug metabolism. ${ }^{54}$

This study has several limitations to consider in the interpretation of results. Efforts were made to harmonise data from different sources and countries; however, both measurement and reporting issues may lead to arbitrary differences between regions and countries. With the exception of the Quebec cohort, treatment indication is unknown. Documentation of health problems in medical services billing data and EMRs was used as a proxy for treatment indication, which based on past studies has a predictive value of $7.8 \%-80.3 \% .{ }^{55}$ The resulting misclassification will attenuate differences observed in treatment approach between conditions. Moreover, diagnoses of health problems tend to be underreported in adminsitrative data. Prescription data were used in the three jurisdictions and may overestimate the incidence and prevalence of antidepressant use as approximately $37 \%$ of antidepressant prescriptions are not filled. ${ }^{56}$ The Ontario, Montreal and Taiwan cohorts represented total populations or representative samples, whereas the UK, Quebec and USA cohorts were assembled on the basis of practices supported by specific information technology systems. The trends observed in these more selected populations, however, are similar to those reported for antidepressant use in older adults in these countries. ${ }^{67-62}$

In conclusion, antidepressant use in older adults varies up to 24-fold by country (cumulative incidence from $0.7 \%$ to $17.0 \%$ ), and chronic pain appears to be the most common treatment indication in all jurisdictions, even more so than depression. Evaluation of real-world risks and benefits of antidepressants by treatment indication should be a priority for future research. The relative contraindication of TCAs in older adults because of their potent anticholinergic effects needs to be assessed given their high rate of use and proven efficacy in pain management. ${ }^{39-42}$

\footnotetext{
Author affiliations

${ }^{1}$ Department of Medicine and Department of Epidemiology and Biostatistics, McGill University, Montreal, Quebec, Canada

${ }^{2}$ Medicine, Brigham and Women's Hospital, Boston, Massachusetts, USA ${ }^{3}$ Epidemiology, Biostatistics and Occupational Health, McGill University, Montreal, Quebec, Canada

${ }^{4}$ Direction de santé publique, Agence de la Santé et des services Sociaux de Montréal, Montreal, Quebec, Canada

${ }^{5}$ Arthritis Research UK Centre for Epidemiology, University of Manchester,

Manchester, UK

${ }^{6}$ Internal Medicine, The Ottawa Hospital, Ottawa, Ontario, Canada

${ }^{7}$ Clinical Epidemiology Program, The Ottawa Hospital Research Institute, Ottawa, Ontario, Canada
}

${ }^{8}$ Clinical and Health Informatics Research Group, McGill University, Montreal, Quebec, Canada

${ }^{9}$ Department of Medicine, Brigham and Women's Hospital, Boston, Massachusetts, USA

${ }^{10}$ Graduate Institute of Biomedical Informatics, Taipei Medical University, Taipei, Taiwan

${ }^{11}$ Department of Medicine, University of Manchester, Manchester, UK

Contributors RT, DWB, DLB, WD, AJF, JH and JL contributed to the study concept and design. NG, TS and BH contributed to the statistical analysis. RT drafted the manuscript. DWB, DLB, WD, AJF, NG, JH, BH, SK, JL and TS critically reviewed the manuscript for intellectual content. All authors read and approved the final manuscript.

Funding This project was funded by the Canadian Institutes of Health Research (CIHR) operating grant \# MOP-111166.

\section{Competing interests None declared.}

Patient consent for publication Not required.

Ethics approval This study received ethics approval from the McGill University Institutional Review Board (IRB \# A01-B02-02A), the Institute for Clinical Evaluative Sciences, the Partners Human Research Committee IRB (Protocol \# 2011P000773/ $\mathrm{PH}$ ) and the Independent Scientific Advisory Committee (ISAC) of CPRD (Protocol \# 14_081R).

Provenance and peer review Not commissioned; externally peer reviewed.

Data sharing statement No additional are data available.

Open access This is an open access article distributed in accordance with the Creative Commons Attribution Non Commercial (CC BY-NC 4.0) license, which permits others to distribute, remix, adapt, build upon this work non-commercially, and license their derivative works on different terms, provided the original work is properly cited, appropriate credit is given, any changes made indicated, and the use is non-commercial. See: http://creativecommons.org/licenses/by-nc/4.0/.

\section{REFERENCES}

1. WHO. Depression. In: Organization WH, (ed), 2017.

2. OECD. Health at a Glance 2015: OECD indictors. OECD Indicators. Paris: OECD Publishing, 2015:217. https://doi. org/10.1787/health_ glance-2015-en

3. Chee KY, Tripathi A, Avasthi A, et al. International study on antidepressant prescription pattern at 40 major psychiatric institutions and hospitals in Asia: A 10-year comparison study. Asia Pac Psychiatry 2015;7:366-74.

4. Burton C, Anderson N, Wilde K, et al. Factors associated with duration of new antidepressant treatment: analysis of a large primary care database. Br J Gen Pract 2012;62:e104-e112.

5. Rotermann M, Sanmartin C, Hennessy D, et al. Prescription medication use by Canadians aged 6 to 79. Health Rep 2014;25:3-9.

6. Pratt LA, Brody DJ, Gu Q. Antidepressant use in persons aged 12 and over: United States, 2005-2008. NCHS Data Brief 2011;76:1-8.

7. Zhong W, Kremers HM, Yawn BP, et al. Time trends of antidepressant drug prescriptions in men versus women in a geographically defined US population. Arch Womens Ment Health 2014;17:485-92.

8. Ivanova JI, Bienfait-Beuzon C, Birnbaum HG, et al. Physicians' decisions to prescribe antidepressant therapy in older patients with depression in a US managed care plan. Drugs Aging 2011;28:51-62.

9. Singh R, Mazi-Kotwal N, Thalitaya MD. Recognising and Treating Depression in the Elderly. Psychiatr Danub 2015;27(Suppl 1):S231-4.

10. PHSA. Chronic disease multi-morbidity. How healthy are Canadians? A Trend analysis of the health of Canadians from a healthy living and chronic disease perspective: Public Health Agency of Canada, 2014:23-4.

11. Wong J, Motulsky A, Abrahamowicz M, et al. Off-label indications for antidepressants in primary care: descriptive study of prescriptions from an indication based electronic prescribing system. BMJ 2017;356:j603.

12. Wong J, Motulsky A, Eguale T, et al. Treatment indications for antidepressants prescribed in primary care in Quebec, Canada, 2006-2015. JAMA 2016;315:2230-2.

13. Eguale T, Buckeridge DL, Winslade NE, et al. Drug, patient, and physician characteristics associated with off-label prescribing in primary care. Arch Intern Med 2012;172:781-8.

14. Chen H, Reeves JH, Fincham JE, et al. Off-label use of antidepressant, anticonvulsant, and antipsychotic medications 
among Georgia medicaid enrollees in 2001. J Clin Psychiatry 2006;67:972-82.

15. Mojtabai R, Olfson M. Proportion of antidepressants prescribed without a psychiatric diagnosis is growing. Health Aff 2011;30:1434-42.

16. Mojtabai R. Diagnosing depression in older adults in primary care. $N$ Engl J Med 2014;370:1180-2.

17. Wang CY, Fu SH, Wang CL, et al. Serotonergic antidepressant use and the risk of fracture: a population-based nested case-control study. Osteoporos Int 2016;27:57-63.

18. Moura C, Bernatsky S, Abrahamowicz M, et al. Antidepressant use and 10-year incident fracture risk: the population-based Canadian Multicentre Osteoporosis Study (CaMoS). Osteoporos Int 2014;25:1473-81.

19. Orriols L, Wilchesky M, Lagarde E, et al. Prescription of antidepressants and the risk of road traffic crash in the elderly: a case-crossover study. Br J Clin Pharmacol 2013;76:810-5.

20. Mclntyre RS, Suppes T, Tandon R, et al. Florida Best Practice Psychotherapeutic Medication Guidelines for Adults With Major Depressive Disorder. J Clin Psychiatry 2017;78:703-13.

21. Kennedy SH, Lam RW, Mclntyre RS, et al. Canadian Network for Mood and Anxiety Treatments (CANMAT) 2016 Clinical Guidelines for the Management of Adults with Major Depressive Disorder: Section 3. Pharmacological Treatments. Can J Psychiatry 2016;61:540-60.

22. APA. The American Psychiatric Association Practice Guidelines for the Psychiatric Evaluation of Adults. 3rd edn: American Psychiatric Association, 2016:170.

23. Mulsant BH, Blumberger DM, Ismail Z, et al. A systematic approach to pharmacotherapy for geriatric major depression. Clin Geriatr Med 2014;30:517-34.

24. NICE. Depression in adults: recognition and management. UK: National Institute for Health and Care Excellence, 2009

25. Kennedy SH, Lam RW, Parikh SV, et al. Canadian Network for Mood and Anxiety Treatments (CANMAT) clinical guidelines for the management of major depressive disorder in adults. Introduction. $J$ Affect Disord 2009;117(Suppl 1):S1-S2.

26. Parikh SV, Segal ZV, Grigoriadis S, et al. Canadian Network for Mood and Anxiety Treatments (CANMAT) clinical guidelines for the management of major depressive disorder in adults. II. Psychotherapy alone or in combination with antidepressant medication. J Affect Disord 2009;117(Suppl 1):S15-S25.

27. Lam RW, Kennedy SH, Grigoriadis S, et al. Canadian Network for Mood and Anxiety Treatments (CANMAT) clinical guidelines for the management of major depressive disorder in adults. III. Pharmacotherapy. J Affect Disord 2009;117(Suppl 1):S26-S43.

28. Tamblyn R, Girard N, Dixon WG, et al. Pharmacosurveillance without borders: electronic health records in different countries can be used to address important methodological issues in estimating the risk of adverse events. J Clin Epidemiol 2016;77:101-11

29. Herrett E, Gallagher AM, Bhaskaran K, et al. Data Resource Profile: Clinical Practice Research Datalink (CPRD). Int J Epidemiol 2015;44:827-36.

30. Lacasse A, Ware MA, Dorais M, et al. Is the Quebec provincial administrative database a valid source for research on chronic noncancer pain? Pharmacoepidemiol Drug Saf 2015;24:980-90.

31. ATC: Structure and Principles. Secondary ATC: Structure and Principles 2018-02-05. https://www.whocc.no/atc/structure and principles/

32. Thompson ML, Myers JE, Kriebel D. Prevalence odds ratio or prevalence ratio in the analysis of cross sectional data: what is to be done? Occup Environ Med 1998;55:272-7.

33. Magrini N, Font M. Direct to consumer advertising of drugs in Europe. BMJ 2007;335:526-26.

34. The development and updating of local formularies, NICE good practice guidance: National Institute for Health and Clinical Excellence (NICE), 2012.

35. Technology appraisal guidance. Secondary Technology appraisal guidance. https://www.nice.org.uk/about/what-we-do/ourprogrammes/nice-guidance/nice-technology-appraisal-guidance

36. CADTH Common Drug Review (CDR). Secondary CADTH Common Drug Review (CDR). https://www.cadth.ca/about-cadth/what-we-do/ products-services/cdr

37. Mansfield KE, Sim J, Jordan JL, et al. A systematic review and metaanalysis of the prevalence of chronic widespread pain in the general population. Pain 2016;157:55-64.
38. Fayaz A, Croft P, Langford RM, et al. Prevalence of chronic pain in the UK: a systematic review and meta-analysis of population studies. BMJ Open 2016;6:e010364.

39. Fennema J, Petrykiv S, de Jonge L, et al. Efficacy and safety of antidepressants as analgesics in chronic pain: A review. European Psychiatry 2017;41:S234.

40. Finnerup NB, Attal N, Haroutounian S, et al. Pharmacotherapy for neuropathic pain in adults: a systematic review and meta-analysis. Lancet Neurol 2015;14:162-73

41. O'Mahony D, O'Sullivan D, Byrne S, et al. STOPP/START criteria for potentially inappropriate prescribing in older people: version 2. Age Ageing 2015;44:213-8.

42. Society AG. Updated Beers Criteria for Potentially Inappropriate Medication Use in Older Adults. J Am Geriatr Soc 2015;63:2227-46.

43. Chew ML, Mulsant BH, Pollock BG, et al. Anticholinergic activity of 107 medications commonly used by older adults. J Am Geriatr Soc 2008;56:1333-41.

44. Pollock BG, Mulsant BH, Nebes R, et al. Serum anticholinergicity in elderly depressed patients treated with paroxetine or nortriptyline. Am J Psychiatry 1998;155:1110-2.

45. Durán CE, Azermai M, Vander Stichele RH. Systematic review of anticholinergic risk scales in older adults. Eur J Clin Pharmacol 2013:69:1485-96.

46. Collamati A, Martone AM, Poscia A, et al. Anticholinergic drugs and negative outcomes in the older population: from biological plausibility to clinical evidence. Aging Clin Exp Res 2016;28:25-35.

47. Bharadwaj P, Pai MM, Suziedelyte A. Mental health stigma. Econ Lett 2017:159:57-60.

48. Hunt M, Auriemma J, Cashaw AC. Self-report bias and underreporting of depression on the BDI-II. J Pers Assess 2003;80:26-30.

49. Cepoiu M, McCusker J, Cole MG, et al. Recognition of depression by non-psychiatric physicians-a systematic literature review and metaanalysis. J Gen Intern Med 2008;23:25-36.

50. Tamblyn R, Huang A, Kawasumi Y, et al. The development and evaluation of an integrated electronic prescribing and drug management system for primary care. J Am Med Inform Assoc 2006;13:148-59.

51. Equale T, Winslade N, Hanley JA, et al. Enhancing pharmacosurveillance with systematic collection of treatment indication in electronic prescribing: a validation study in Canada. Drug Saf 2010;33:559-67.

52. Gelenberg AJF MP, Markowitz JC, Rosenbaum JF. et al. Practice Guidleine for the Treatment of Patients with Major Depressive Disorder: American Psychiatric Association, 2010.

53. Treuer T, Liu CY, Salazar G, et al. Use of antidepressants in the treatment of depression in Asia: guidelines, clinical evidence, and experience revisited. Asia Pac Psychiatry 2013;5:219-30.

54. Kirchheiner J, Nickchen K, Bauer M, et al. Pharmacogenetics of antidepressants and antipsychotics: the contribution of allelic variations to the phenotype of drug response. Mol Psychiatry 2004;9:442-73.

55. Wong J, Abrahamowicz M, Buckeridge DL, et al. Assessing the accuracy of using diagnostic codes from administrative data to infer antidepressant treatment indications: a validation study. Pharmacoepidemiol Drug Saf 2018;27:1101-11.

56. Tamblyn R, Eguale T, Huang A, et al. The Incidence and Determinants of Primary Nonadherence With Prescribed Medication in Primary Care: A Cohort StudyPrimary Nonadherence With Prescribed Medication in Primary Care. Ann Intern Med 2014;160:441-50.

57. Gobert M, D'hoore W. Prevalence of psychotropic drug use in nursing homes for the aged in Quebec and in the French-speaking area of Switzerland. Int J Geriatr Psychiatry 2005;20:712-21.

58. Beck CA, Williams JV, Wang JL, et al. Psychotropic medication use in Canada. Can J Psychiatry 2005;50:605-13.

59. Beck CA, Patten SB, Williams JV, et al. Antidepressant utilization in Canada. Soc Psychiatry Psychiatr Epidemiol 2005;40:799-807.

60. Lewer D, O'Reilly C, Mojtabai R, et al. Antidepressant use in 27 European countries: associations with sociodemographic, cultural and economic factors. Br J Psychiatry 2015;207:221-6.

61. Petty DR, House A, Knapp P, et al. Prevalence, duration and indications for prescribing of antidepressants in primary care. Age Ageing 2006;35:523-6

62. Mark TL, Joish VN, Hay JW, et al. Antidepressant use in geriatric populations: the burden of side effects and interactions and their impact on adherence and costs. Am J Geriatr Psychiatry 2011;19:211-21. 